\title{
Springback optimization in automotive Shock Absorber Cup with Genetic Algorithm
}

\author{
Ganesh Kakandikar, ${ }^{1, *}$ and Vilas Nandedkar ${ }^{2}$ \\ 1 MAEER's Maharashtra Institute of Technology, Pune, Maharashtra, India \\ ${ }^{2}$ SGGS Institute of Engineering and Technology, Nanded, Maharashtra, India
}

Received: 28 September 2017 / Accepted: 10 November 2017

\begin{abstract}
Drawing or forming is a process normally used to achieve a required component form from a metal blank by applying a punch which radially draws the blank into the die by a mechanical or hydraulic action or combining both. When the component is drawn for more depth than the diameter, it is usually seen as deep drawing, which involves complicated states of material deformation. Due to the radial drawing of the material as it enters the die, radial drawing stress occurs in the flange with existence of the tangential compressive stress. This compression generates wrinkles in the flange. Wrinkling is unwanted phenomenon and can be controlled by application of a blank-holding force. Tensile stresses cause thinning in the wall region of the cup. Three main types of the errors occur in such a process are wrinkling, fracturing and springback. This paper reports a work focused on the springback and control. Due to complexity of the process, tool try-outs and experimentation may be costly, bulky and time consuming. Numerical simulation proves to be a good option for studying the process and developing a control strategy for reducing the springback. Finite-element based simulations have been used popularly for such purposes. In this study, the springback in deep drawing of an automotive Shock Absorber Cup is simulated with finite element method. Taguchi design of experiments and analysis of variance are used to analyze the influencing process parameters on the springback. Mathematical relations are developed to relate the process parameters and the resulting springback. The optimization problem is formulated for the springback, referring to the displacement magnitude in the selected sections. Genetic Algorithm is then applied for process optimization with an objective to minimize the springback. The results indicate that a better prediction of the springback and process optimization could be achieved with a combined use of these methods and tools.
\end{abstract}

Keywords: deep drawing / springback / FE simulation / taguchi method / Genetic Algorithm / optimization

\section{Introduction}

Automotive parts, aerospace components as well as consumer products like kitchen sinks, cans, boxes, etc. are manufactured by class of metal forming processes. These are broadly classified as forming/drawing/stamping and deep drawing operations, which include a wide variety of material processing and flow conditions. Deep drawing combines both compressive as well as tensile stresses [1]. The draw punch shapes the blank inside the die cavity for required shape. Large plastic deformation needs to be achieved in deep drawing. It is observed that, still sheet metal industry works with trial and error approaches to achieve optimum process parameters. Many parameters are involved in the process with interdependence. These

\footnotetext{
* e-mail: kakandikar@gmail.com
}

can be classified as properties of materials, parameters of process including tool and die geometry and component dimensions.

The cup to be formed as ideal component deep drawing has three different regions of deformations as shown in Figure 1 in a pi shaped section. The punch wraps the material around it at the center of blank. Biaxial stresses are induced in this region with punch progress. The rim of blank is pulled inside towards die center [2]. Due to this radius of blank reduces slowly to achieve the that of drawn component. Compressive strain in the direction of circumference and tensile along radius are continuously balanced in this process as shown in Figure 2.

These major strains result in increase in the thickness with sheet inward travel in flange region. The metal is bent and straightened over die edge. Plastic deformation results in considerable reduction in thickness, which balances the thickening due to the circumferential shrinking. The proposed innovative methodology combines two techniques for optimization of springback in automotive Shock 


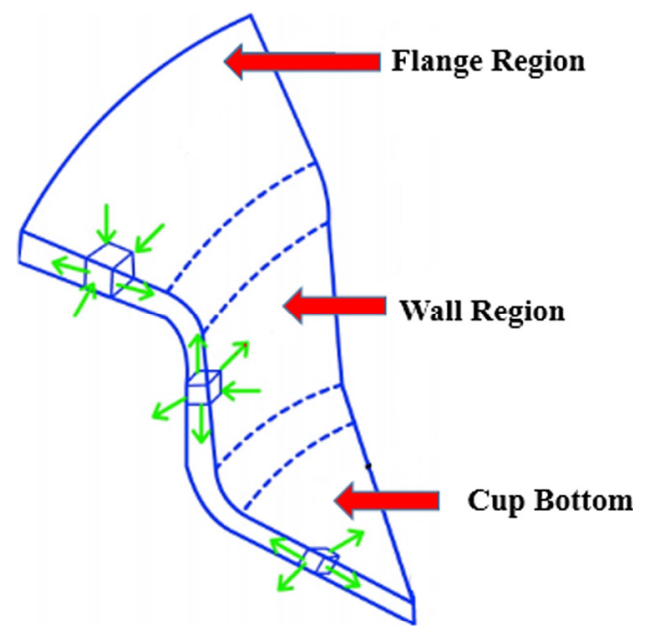

Fig. 1. State of stress in pi shaped section.

Absorber Cup. Taguchi design of experiments and analysis of variance is used to analyze the influencing process parameters on springback. Mathematical relations have been developed to relate input process parameters and springback. Optimization problem has been formulated for springback displacement magnitude. Genetic Algorithm is applied for optimization.

\section{Springback in metal forming}

Springback is defined as elastic deformation and shape change of the component that happens after deformation and removal of drawing force [3]. Springback is one of the most important performance parameters in sheet forming as it is related to the size and shape of the object to be formed. Elastic recovery of the deformed component, e.g. due to elastic relief with applied bending moment in a forming process, may cause this error. Springback occurs in many manufacturing processes where material deformations happen [4]. Cold working processes are more prone to springback. A material deformation may start in an elastic region and then proceeds to the plastic zone. When the load is removed, the strain reduces for an amount for elastic deformation with reduction in stress generating the springback [5]. Control of the springback by accurate prediction is possible, depending on appropriate design and analysis tools [6].

Chaudhari and Patil studied effect of process parameters such as die shoulder radius, punch nose radius and sheet thickness, on springback. The springback may be controlled through controlling the thickness of sheet metal [7]. Singh and Agnihotri reviewed various parameters and their influences on springback such as friction, blank holding force, punch speed and blank shape [8]. Zein et al. studied effect of the die shoulder on springback and found that the radius should be 10 times of the sheet thickness in order to reduce it. In addition, geometry of the punch influences the springback of the sheet metal blank in the deep drawing. If punch nose radius is greater than six times of the thickness of the blank, the cup have small values for the springback [9]. Oujebbour et al. applied simulated annealing for optimizing springback. The obtained Pareto fronts were similar to the ones yielded by the NSGA-II method, while they needed much less cost evaluations [10]. Tang et al. applied projection-based heuristic global search algorithm for springback optimization [11]. Based on finite element analysis, the optimization of sheet metal forming process was accomplished by using the kriging approximate ability and the global optimization ability of evolutionary strategy for minimum springback by Praveen Kumar and Lee. The process inputs were punch radius and clearance gap and main output was springback angle [12].

This paper presents a novel methodology for predicting and controlling the springback in deep drawing. Numerical experiments were conducted based on Taguchi design of experiments and then analysis of variance was carried out to identify sensitive parameters. Based on the process variability in experimentation, a mathematical model was formed through regression analysis of the springback relating to the process parameters. This mathematical model was treated as an objective function for the following optimization, based on using an Genetic Algorithm.

\section{Influential process parameters involved}

Numerical investigations presented in this paper contain four major process parameters that have been studied to establish the effect on springback. These are blank holding force $(\mathrm{BHF})$, lubrication, die profile radius and punch nose radius.

\subsection{Blank-holding force}

The blank holder controls the travel of material in the die. It greatly determines the plastic deformation and product quality. It will assure uniform thickness distribution in drawn part. The two opposite behaved failures i.e. wrinkling and tearing, can only be avoided with optimum blank force. If the BHF applied is less, it allows free flow of the material in the die which leads to wrinkling in walls. On the other hand, too high $\mathrm{BHF}$ will restrict the flow and this can cause cracking in the material with punch action. Various researchers have experimented with even variable BHF. The Siebel's equation is used for calculation of the $\mathrm{BHF}$. The investigations in this work are carried out by application of a constant BHF.

\subsection{Friction}

Friction forms essential part of the process. Lubrication is needed to control the friction. Parameters as material properties, surface finish, temperature, sliding velocity and contact pressure determines the lubricant characteristics. Lubrication is normally expressed in terms of coefficient of friction. In metal forming there are many contact areas where sheet and tool has relative motion with each other, friction plays an important part [13]. The friction between punch and sheet basically results into deformation. The corner of the die, where sheet slides and shears continuously, influences the coefficient which is mostly considered to be in between 0.05 and 0.15 . The defects and part quality 


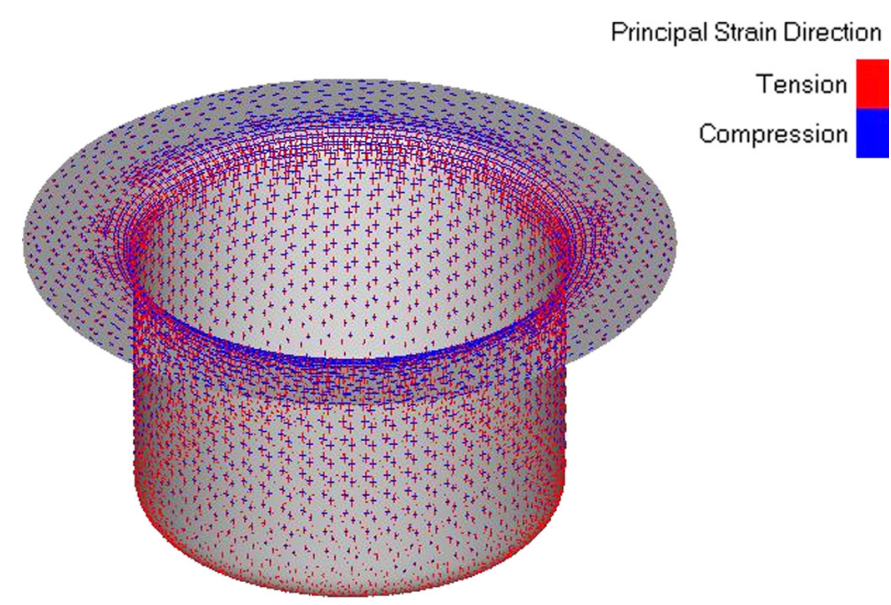

Fig. 2. Principle strain directions in deep drawing.

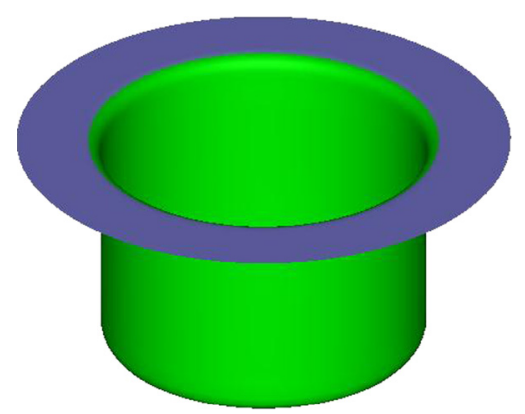

Fig. 3. Shock Absorber Cup.

is determined by control of friction. Tool wear and associated manufacturing expenses are also dependent on lubrication.

There can be film lubrication and full lubrication. Dry lubrication refers to the use of solid lubricants, which are not applied generally in metal forming. A dry condition assumes complete absence of lubrication at mating surfaces, so friction is high. Dry lubrication is applied when material formability is very high and simple parts can be drawn without lubrication, without affecting part quality [14]. When the solid surfaces are close together, Film lubrication is applied. Mating surfaces are fully separated by a thin film in full film lubrication. Schey [15] has defined six contact and friction regions in deep drawing. Wrinkling is resulted with poor friction and flow control of sheet. Whereas excessive friction leads to crack formation or tearing. Petroleum-based oils and soluble oils are generally applied in metal forming. Method of lubrication, additives and corrosion control are the factors for selection of appropriate lubricant.

It is observed that, most of the small scale manufacturers of sheet metal in and around Pune, which is known as Detroit of India works on trial and error. Process parameters are selected based on experience, knowledge and intuition of worker. So many times, it takes long duration to arrive at optimum combination of parameters. Also they prefer locally available cheaper oils for lubrication purpose. This affects the badly on the quality of manufactured products.

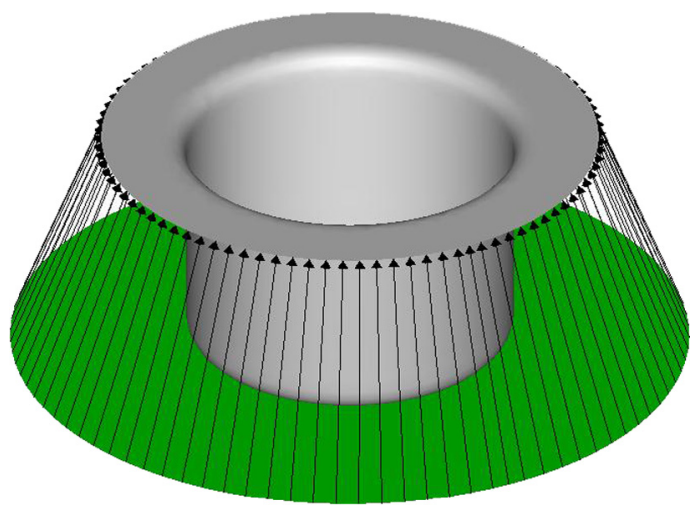

Fig. 4. Shock Absorber Cup-edge displacement.

\subsection{Punch nose radius}

Punch is operated with flywheel in mechanical systems. Punch force determines the deformation required convert blank into finished product by flowing it inside die. The face of punch and punch nose radius must be carefully designed. Too small punch nose radius can pierce or cut the blank instead of forcing the material to bend around the radius [16]. Material and its thickness will determine the appropriate punch nose radius. As the punch nose radius increases, the possibility of blank to stretch rather than draw in blank edge.

\subsection{Die profile radius}

With flat blank holder radius of die profile and its surface plays important role in flowing of sheet into cavity [17]. As the material deforms and if the die profile radius is smaller, the sheet may split. This is resulted due to high restraining forces initiated with bending and unbending of the sheet metal over a tight radius. Tight radius of die may also cause lot of heat generation. Therefore, galling happens, means the sheet metal microscopically welds to the tool. On the contrary, excessive die radius is also not advised. There is possibility that the sheet metal wrinkle in between punch and die face. Adequate experience and intuition helps in deciding a range of die profile radius which works properly.

\section{Shock Absorber Cup - analysis case}

Shock Absorber Cup is manufactured by Vishwadeep Enterprises, Chikhali, Pune, India for A. V. Industries. The component, as the name indicates is a part of two wheeler shock absorber assembly. This is a good example of a typical deep drawn cup with flange, as shown in Figure 3. The flange shows wrinkling tendency. When the flat blank is converted to the required shape by the punch and die, every point of the blank travels by following a path until the component is fully formed: the process is represented with edge displacements, as shown in Figure 4. The cup has a flange diameter of $69 \mathrm{~mm}$ and cup diameter of $40 \mathrm{~mm}$. The total height is $31.5 \mathrm{~mm}$. The cup has flat bottom of $40 \mathrm{~mm}$ diameter with corner radius of $2.5 \mathrm{~mm}$. The corner radius at flange is $2 \mathrm{~mm}$. The material is D-513 with UTS $315 \mathrm{MPa}$ and thickness $0.8 \mathrm{~mm}$. 
Table 1. L9 Orthogonal array for Shock Absorber Cup.

\begin{tabular}{|c|c|c|c|c|c|}
\hline & & Lower & & Middle & Upper \\
\hline$B H F$ & & $08 \mathrm{kN}$ & & $10 \mathrm{kN}$ & $12 \mathrm{kN}$ \\
\hline$\mu$ & & 0.05 & & 0.10 & 0.15 \\
\hline$R_{D}$ & & $1.5 \mathrm{~mm}$ & & $2.0 \mathrm{~mm}$ & $2.5 \mathrm{~mm}$ \\
\hline$R_{P}$ & & $6.0 \mathrm{~mm}$ & & $7.0 \mathrm{~mm}$ & $8.0 \mathrm{~mm}$ \\
\hline Expt. no. & Blank holding force & & Coefficient of friction & Die profile radius & Punch nose radius \\
\hline 1 & 10 & & 0.05 & 1.5 & 6.0 \\
\hline 2 & 10 & & 0.10 & 2.0 & 7.0 \\
\hline 3 & 10 & & 0.15 & 2.5 & 8.0 \\
\hline 4 & 15 & & 0.05 & 2.0 & 8.0 \\
\hline 5 & 15 & & 0.10 & 1.5 & 6.0 \\
\hline 6 & 15 & & 0.15 & 1.5 & 7.0 \\
\hline 7 & 20 & & 0.05 & 2.5 & 7.0 \\
\hline 8 & 20 & & 0.10 & 1.5 & 8.0 \\
\hline 9 & 20 & & 0.15 & 2.0 & 6.0 \\
\hline
\end{tabular}

\section{Design of experiments - orthogonal arrays}

The Taguchi design of experiments talks about controlling the process variability through robust experimentation design. It was developed by Dr. Genichi Taguchi of Japan. The methodology deals with detail study of influence of input parameters on output performance of the process in designed experiments. The variance is process with mean is studied, by which proper functioning of the process is assured. Taguchi developed orthogonal arrays instead of full factorial to correlate the parameters affecting the process and their levels of variation. Instead of having to test all possible combinations like the factorial design, the Taguchi method tests pairs of combinations [18].

Minimum experimentation saves time and efforts with collection of data about dominant parameters affecting product quality. During present investigations for automotive Shock Absorber Cup, four parameters are selected as BHF, lubrication-coefficient of friction $(\mu)$, punch nose radius $\left(R_{P}\right)$ and die profile radius $\left(R_{D}\right)$. Three levels of each parameter are selected. Taguchi suggests L9 orthogonal array for four parameters and three levels. The design along with three levels of parameters is presented in Table 1 [19] (Fig. 5).

\section{Numerical simulations}

Numerical simulations of sheet metal forming processes, based on finite element method (FEM), represent a powerful tool for prediction of forming processes and are used worldwide [20]. Numerical simulations have been carried out for all the nine designed experiments using commercial platform Forming Suite. It uses LS-DYNA explicit incremental solver for the most accurate formability simulation results. Solid shell elements were applied from the LS Dyna solver for meshing. The material data, elastic behavior and yield curves, was obtained from a standard material test. Plastic anisotropy was considered, based on Hills theory. One of the major reasons of rejection in deep drawn parts is due to springback as the springback modifies the shapes of drawn components and they deviate from original design. Therefore, the springback displacement magnitude is measured in the numerical experiments as response. The above figures elaborate the state of Springback in all the nine experiments designed. The various color regions show different springback displacement magnitudes in $\mathrm{mm}$. The highest springback magnitude is in the flange region, represented in red colour. The minimum springback observed in all experiments is $0.006 \mathrm{~mm}$ and maximum $0.079 \mathrm{~mm}$.

\section{Analysis of variance}

To establish the relationships between selected process parameters and springback, analysis of variance is carried out after experimentation. The $S / N$ ratios were calculated for minimizing the springback, criterion selected is minimum the better. The formula applied is

$$
\begin{array}{r}
S / N=-10 \log [\text { sum of square of spring } \\
\text { back displacement magnitude }] .
\end{array}
$$

Table 2 represents the springback displacement magnitudes for all experiments in simulations of Shock Absorber Cup.

The maximum springback displacement magnitude is $0.079 \mathrm{~mm}$ and minimum is $0.071 \mathrm{~mm}$. The mean $S / N$ ratios are calculated for all parameters blank holding force, coefficient of friction, die profile radius and punch nose radius at all three levels low, medium and high as shown in Table 3. The range is defined as the difference between maximum and minimum value of $S / N$ ratio for particular parameter. Higher the range higher is rank indicates that the parameter is more sensitive and influential on response. The results of orthogonal array indicate that friction has 

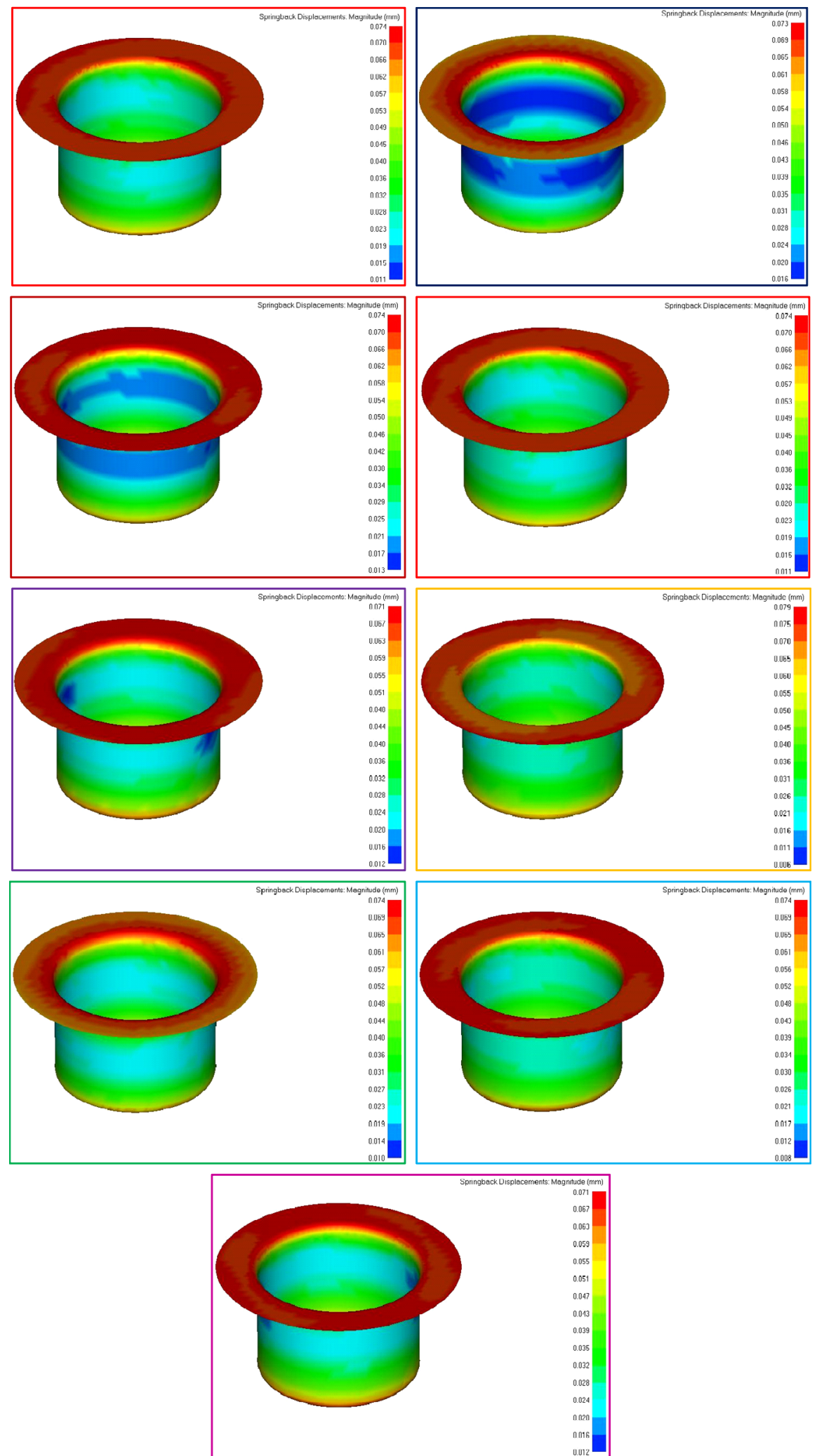

Fig. 5. Shock Absorber Cup-springback displacement magnitude in nine experiments.

major influence on springback. Punch nose radius has second rank; Blank holding force has third rank and die profile radius has least influence. To control the spring- back, coefficient of friction, i.e., lubricating condition, and punch nose radius, must be precisely controlled or designed. 
Table 2. $S / N$ ratios Shock Absorber Cup.

\begin{tabular}{lll}
\hline \multicolumn{2}{l}{ Expt. no. Springback displacement magnitude $S / N$ ratios } \\
\hline 1 & $0.074 \mathrm{~mm}$ & 22.61 \\
2 & $0.073 \mathrm{~mm}$ & 22.73 \\
3 & $0.074 \mathrm{~mm}$ & 22.61 \\
4 & $0.072 \mathrm{~mm}$ & 22.85 \\
5 & $0.071 \mathrm{~mm}$ & 22.97 \\
6 & $0.079 \mathrm{~mm}$ & 22.04 \\
7 & $0.074 \mathrm{~mm}$ & 22.61 \\
8 & $0.074 \mathrm{~mm}$ & 22.61 \\
9 & $0.071 \mathrm{~mm}$ & 22.97 \\
\hline
\end{tabular}

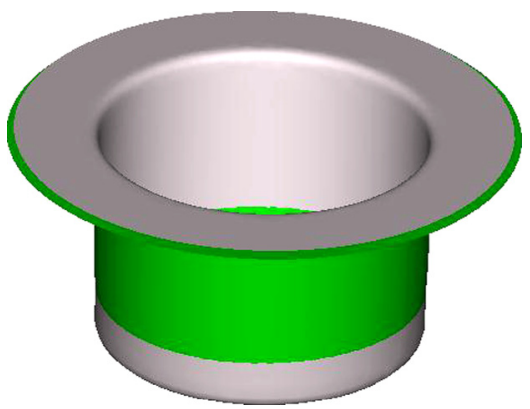

Fig. 6. Springback observed in the flange in numerical simulation.

\section{Mathematical modeling and problem formulation}

Linear relationship has been established between four input parameters and performance measure as springback using regression analysis. Minitab is used for linear regression. Springback is correlated with process parameters. The drawing ratio is a major constraint, when working with deep drawn components. The correlation of the die profile radius and the punch nose radius forms the second constraint. The cracking load must be avoided, and hence, it is the third constraint. Finally, the relation between the cup diameter, thickness and die profile radius, forms the last constraint.

$$
\begin{aligned}
\mathrm{SDM} & =0.0739-0.000067 B H F+0.0133 \mu \\
& -0.00267 R_{D}+0.00067 R_{P} .
\end{aligned}
$$

An optimization problem has been formulated with the following constraints:

Minimize $F$,

$$
\begin{aligned}
F & =0.0739-0.000067 B H F+0.0133 \mu-0.00267 R_{D} \\
& +0.00067 R_{P}
\end{aligned}
$$

Subjected to $1.2 \leq \beta \leq 2.2,3 R_{D} \leq R_{P} \leq 6 R_{D}$

$$
F_{d \max } \leq \pi d_{m} S_{0} S_{u}, R_{D} \geq 0.035\left[50+\left(d_{0}-d_{1}\right)\right] \sqrt{S_{0}}
$$

Table 3. Analysis of variance.

\begin{tabular}{lllll}
\hline & $B H F$ & $\mu$ & $R_{D}$ & $R_{P}$ \\
\hline 1 & $22.66 \mathrm{kN}$ & 23.19 & $22.73 \mathrm{~mm}$ & $22.64 \mathrm{~mm}$ \\
2 & $22.77 \mathrm{kN}$ & 23.01 & $22.85 \mathrm{~mm}$ & $22.32 \mathrm{~mm}$ \\
3 & $22.56 \mathrm{kN}$ & 21.79 & $22.54 \mathrm{~mm}$ & $23.04 \mathrm{~mm}$ \\
Range & 0.21 & 1.40 & 0.19 & 0.72 \\
Rank & 3 & 1 & 4 & 2 \\
\hline
\end{tabular}

Table 4. Results of optimization.

\begin{tabular}{llll}
\hline Parameter & $\begin{array}{l}\text { Lower } \\
\text { bound }\end{array}$ & $\begin{array}{l}\text { Upper } \\
\text { bound }\end{array}$ & Optimum \\
\hline Flange diameter & $67 \mathrm{~mm}$ & $71 \mathrm{~mm}$ & $69.97 \mathrm{~mm}$ \\
$\begin{array}{c}\text { Friction coefficient } \\
\text { Springback displacement } \\
\text { magnitude }\end{array}$ & 0.05 & 0.15 & 0.057 \\
\hline
\end{tabular}

\section{Optimization with Genetic Algorithm}

Genetic Algorithm is an optimization method based on human evolution, which can be iplemented by computer programming [21]. It mimics the principle of genetics stating survival of fittest. In sixties Professor John Holland proposed this technique [22]. It works on combination of fittest string structures with a structured yet randomized search. In every generation, new off springs are created from parents keeping some proportion of parent's also. It is executed with three steps reproduction, crossover and mutation [23]. Reproduction selects fit population from randomly generated. Cross over results into major information exchange and global search. Whereas mutation implements local search. Genetic Algorithm works with population and hence, explores global space. It can handle all types of variables and objective function, convex or concave. Probabilities overcomes a deterministic approach. In present study, Genetic Algorithm is applied for optimization of springback. Flange diameter and friction coefficient are kept as variables. The ranges for the variables and the results are presented in Table 4 (Fig. 6).

\section{Conclusions}

By a combined use of Taguchi design of experiments, FE simulation, mathematic modelling and Genetic Algorithm, deep drawing of an automotive component is simulated and the process optimized. For the case tested, it shows that, with the proposed optimization approach, the springback of the cup drawn could be reduced by, approximately, $50 \%$, when the flange diameter was set properly and the friction condition controlled at a proper level, e.g. corresponding to a coefficient of friction 0.05. By knowing the optimal 
coefficient of friction, suggested by the Genetic Algorithm, one could pre-select proper lubricant and control the state of the lubrication during deep drawing, with a view to reducing the springback of the component to be drawn. The same can be said on the pre-determination of the geometry of the metal blanks to be drawn. The approach presented in this paper could help to improve the efficiency of the design and manufacture process involved in a product development with deep drawing of sheet metals.

\section{References}

1. G.M. Kakandikar, V.M. Nandedkar, J. Comput. Des. Eng. 3, 63-70 (2016)

2. G.M. Kakandikar, V.M. Nandedkar, Int. J. Comput. Aided Eng. Technol. (IJCAET) 5, 362-374 (2013)

3. Thomas Gnaeupel-Herolda, T. Foecke, Henry J. Prask, Richard J. Fields, Mater. Sci. Eng.: A 399, 26-32 (2005)

4. H.K. Yi, D.W. Kim, C.J. Van Tyne, Y.H. Moon, Proc. Inst. Mech. Eng. C: J. Mech. Eng. Sci. 222, 117-129 (2008)

5. M. Kadkhodayan, R. Pourhasan, Majlesi J. Mech. Eng. 3, 1$10(2010)$

6. W. Liu, Q. Liu, F. Ruana, Z. Liang, H. Qiu, J. Mater. Process. Technol. 187-188, 227-231 (2007)

7. S.S. Chaudhari, N.K. Patil, Int. J. Eng. Dev. Res. 3, 906-912 (2015)

8. C.P. Singh, G. Agnihotri, Int. J. Sci. Res. Publ. 5, 1-15 (2015)
9. H. Zein, M.E. Sherbiny, M. Abd-Rabou, M.E. Shazly, Mater. Des. 53, 797-808 (2014)

10. F.-Z. Oujebbour, R. Ellaia, A. Habbal, Concurrent optimization of springback and failure in stamping processes, in 10th World Congress on Structural and Multidisciplinary Optimization, Orlando, Florida, USA, 2013

11. L. Tang, H. Wang, G. Li, Mater. Des. 43, 426-437 (2013)

12. S.P. Praveen Kumar, S.-S. Lee, Int. J. Mech. Syst. Eng. 3, 15 (2017)

13. E. Schedin, Mater. Des. 14, 127-129 (1993)

14. T. Altan, A.E. Tekkaya, Sheet Metal Forming: Fundamentals (ASM International, Ohio, 2012)

15. J.A. Schey, Tribology in Metalworking - Friction,Lubrication and Wear (ASM, Metals Park, Ohio, USA, 1983)

16. W.K. Jawad, J.H. Mohamed, Eng. Technol. 26, 55-73 (2008)

17. W. Gan, R.H. Wagoner, Int. J. Mech. Sci. 46, 1097-1113 (2004)

18. G. Venkateswarlu, M.J. Davidson, G.R.N. Tagore, Int. J. Eng. Sci. Technol. 2, 41-49 (2010)

19. M.T. Browne, M.T. Hillery, J. Mater. Process. Technol. 136, 64-71 (2003)

20. G. Gantar, T. Pepelnjak, K. Kuzman, J. Mater. Process. Technol. 130-131, 54-59 (2002)

21. H. Naceur, Y.Q. Guob, J.L. Batoz, J. Mater. Process. Technol. 151, 183-191 (2004)

22. D.E. Goldberg, Genetic Algorithms in Search, Optimization \& Machine Learning (Pearson Education Pvt. Ltd., India, 2003)

23. G. Gantar, K. Kuzmana, B. Filipi, J. Mater. Process. Technol. 164-165, 1343-1350 (2005)

Cite this article as: Ganesh Kakandikar, Vilas Nandedkar, Springback optimization in automotive Shock Absorber Cup with Genetic Algorithm, Manufacturing Rev. 5, 1 (2018) 